\title{
PIEDRAS DE \\ FRANCISCO GAZITÚA
}

\section{EDUARDO MEISSNER*}

U

NA GENTIL invitación a visitar su cantera-casa de habitar-taller, situada en una encrucijada de vertientes y acantilados del Valle del Maipo, se convertiría en una incursión más que fascinante a un mundo de piedras desprendidas de su napa originaria. Haciéndolas saltar, desu filón de cantera las convierte, sin esfuerzo aparente, en depositarias de un nuevo, sorprendente y misterioso designio. Llamando a su contemplación atenta, se llenan de un nuevo sentido.

Un camino serpenteante, de vueltas en ocasiones en redondo, puentes rústicos sobre hondonadas y desfiladeros, nos habían conducido por laderas y colinas a este caserío de funciones múltiples. Las casas entre árboles de flora nativa y piedras, a medio camino entre las cumbres cordilleranas y los fal deos del río abajo, los vanos de la selva como asomados a las lejanías del valle en la distancia, las brumas al acecho.

Francisco Gazitúa nos recibecon muestras festivasy hospital arias deamistad. El lugar de aparcamiento para el vehículo está ahí, a la vera de la cantera originaria, de los acantilados de granito (de mármol, diría Ernst Jünger), el lugar de pronto lleno de piedras ancestrales, desprendidas del filón, puestas ahí sobre mesas monolíticas, a medio hacer y labrar las piedras, asomadas a su nuevo destino de transformaciones más que necesarias.

Algunos techos artesanales protegen de aguaceros, y sobre los taludes de más allá, piedras grandes, redondas como huevos prehistóricos, nos recuerdan los momentos iniciales deaquellos cien años desoledad 'marquecianos', que de pronto parecen haberse apoderado de las piedras, los troncos rugosos, los emboscamientos telúricos.

*Pintor, ensayista. Ha publicado La configuración espacial (I y II), Semiótica de la arquitectura, Teoría del signo en arquitectura, La domesticación de los pájaros (novela). 
Las constelaciones pétreas, sobre los plafones extendidos, de formas canteadas las unas, perforadas y cribosas las otras, se disponen, agrupan, conforman un aparente desorden al eatorio, como puestas ahí y olvidadas.

Deambulamos demesón en mesón, delugar en lugar, de constelación en constelación, atraídos por las señales de un orden cada vez más ostensible queemerge de las piedras mismas, orden a las que han sido sometidas por la mano del escultor y sus afanes de interventor demiurgo. Senos antoja decir, de buceador en las mi smas sugerentes configuraciones agazapadas en la piedra en busca delasinflexiones posibles tendientes a revelar su oculto misterio.

Algunas piedras se yerguen, rugosas, de manto curvo como desgastadas por lasinclemencias de un tiempo milenario, corteza no tocada por el cincel del escultor, deaperturas orgánicas y redondas, pulidas, conformando oquedades como nichos, hornacinas, espacios para guardar presencias atisbadas, imaginadas de un culto perdido en el tiempo.

Pienso en un espacio interior conformado según las exigencias de una topología originada y proyectada desde la misma figura-deidad mítica puesta ahí, ahora ausente, depositaria la oquedad de la sola forma espacial que envolviera su imaginaria presencia, siendo moldeada, inequívocamente, por ella.

¡Tan insistentes se nos antojan aquellas oquedades, guardianas silenciosas de un templo que fue!

M ás allá, una forma monolítica, gruesa, de cantos redondos y sucesivos, aparece surcada de una red de líneas sutiles a modo de hendiduras-límite. Estamos sin duda frente a un modelo para armar, para desarmar y luego recomponer las piezas, encajando perfectamente en el juego que restaura e instaura la total idad originaria. Cortázar estaría feliz con este cordillerano "modelo para armar".

Camino a la casa del artista, nos topamos con una extensa mesa de bloques articulados de granito que imprimen una horizontalidad imperiosa al lugar a la vera de muros de contención de piedra laja, flora autóctona y agaves.

Socavada del mismo filón enunciado circundando el plano del bloque tendido por bancas arrancadas, también, de la veta madre y dispuestas irregularmente en torno, nos da pronto la sensación de estar frente a un lugar de rituales rotundos, míticos tal vez, telúricos diría el poeta, de iniciaciones cordillera adentro, de inmersiones en un mundo de hábitos atemporales. Dispuestos los bloques para un ceremonial anunciado, quizás en espera de un solsticio equinoccial, un sorpresivo cambio de conciencia, el advenimiento de un nuevo día, están ahí quizás sólo para cel ebrar una vez más el reiterado ritual de una amistad nunca perdida, al gún reencuentro fortuito, una celebración necesaria tomando vino grueso color sangre de toro en grandes pocales de estaño bajo las estrellas con ampulosos movimientos de brazo, y cantos órficos hasta el amanecer. 
Francisco Gazitúa nos habla luego de su trayectoria de artista, su viaje interminable en busca de nuevas esencias, nuevas decapitaciones, nuevas transparencias de realidad. No es circunstancial ni azarosa su decisión de retirarse de la urbe populosa para ir a instalarse en un risco cordillerano, real nido de águilas asomado a un pródigo enclave de granito y piedra laja.

Sus contactos existenciales son generosos y lo relacionan con facilidad y empatía ostensibles a lugares de excepción, personajes consagrados de perfecciones más que preciadas, culturas diversas, diferenciaciones sutiles, ámbitos de selección, moviéndose con soltura y naturalidad entre los polos del viejo continente y las inquietantes soledades de nuestra cordillera andina, circunstancias que han contribuido a forjar, como desdesiempre, las condiciones de nuestra identidad fragmentaria, polifacética, cambiante, fugaz, en ocasiones rotunda.

Permítaseme, a modo de corolario acerca de su quehacer plástico, establecer al gunos rasgos de analogía de su actitud creadora con aquella que se desprendedela obra deSir Antony Caro, escultor inglés con el que, en tiempos paralelos en ocasiones compartidas, recorrerían espacios similares. No hay duda que tanto la obra de Caro como la de Gazitúa se nutren de una actitud minimalista, considerando la realización de estructuras mínimas no por efectos de tamaño y escala reducida, sino por su elementaridad en la elección de los medios, sujetos las más de las veces a una suerte de reduccionismo elemental, y por la constante ruptura y abandono de los principios dela "buena forma" consagrada, y de los principios dearticulación habituales entre estas formas constituyentes, en busca de una novedosa, inusitada, insospechada manera de unir y articular aquel nuevo mundo de signos en obra, que dela presencia en alto grado significativa de los niveles semánticos de sus afanes configurativos no puede haber duda al guna.

Tanto Caro como también Gazitúa van en busca de un proceso de significación más que aparente que confiere a estas obras naturaleza y carácter de signo, estructurados y dispuestos en una suerte de lenguaje plástico renovado, sorprendente, en esencia inusitado.

Los niveles de representatividad icónica se dispersan y concretan aquí en un mundo de señales y símbolos, cuya parcial, sólo parcial, decodificación se nos convierte en aventura fascinante (Ya sabemos que la decodificación completa y total de una obra, objeto estético por lo demás, conduce a la pérdida progresiva de la información estética inherente y respectiva). Y, en el marco de esta semiosis reiterada, se mueve un universo de proyecciones creativas de monumentalidad manifiesta. Un estudio más acabado de estas proyecciones señalizadoras y simbolizantes excedería el campo esquemático de esta presentación.

Mientras que el minimalismo primero de Antony Caro se solaza en la disposición desacostumbrada de varillas y planchas de metal pintadas de un color esencial, de preferencia el amarillo, de formas rectilíneas y angulosas, 
encontramos en las estructuras forjadas de Gazitúa (dela década del noventa) una constante transformación de tensiones lineales diagonales en desarrollos curvos y perfiles de organicidad manifiesta que, dentro de su minimalismo constitutivo, seconvierten en los indicadores de un movimiento contenido de proyecciones múltiples.

La transformación de desnudos femeninos en aéreas estructuras deacero forjado toman aquí visos de paradigma (Colección Andes, 1995).

Las obras de Caro se complejizan progresivamente, aumentan de tamaño, organizan metales y planchas diversas, logrando reales macro-constelaciones heterodoxas, despliegues escenográficos, esculturas recorribles y habitables (After Olympia, 1987; Night mouvements, 1990; Octagon Tower, 1991, de accesos y espacios interiores recorribles).

En Gazitúa, el progresivo cambio de escala y tamaño se presenta generosa - profusa-, exuberantemente en sus "Buques de acero" de concreciones, encuentros y dispersiones metálicos de planchas y fierros en "deformación" constante. Estamos frente a una suerte de mancorna de los mil demonios, de corte más que minimalista. El repertorio se impone, se nos impone, imperativamente. Su "Rueda de Larmahue", para el Museo Interactivo del M irador deSantiago de Chile, reconstruye, remodela, reestructura en esencia las funciones primarias atribuidas a las ruedas de agua originales, convertida la escultura entera en paisaje recorrible, extendido, surreal. Afanes reductivos necesarios llevan a Caro a redescubrir artesanías ancestrales, maternales, planchas y planchones de madera carcomidos por el tiempo, en la presencia sugerente y mítica del barro cocido. Su "Juicio final" del M useo Würth expuesto en la Bienal 48 de Venecia (en 1999) recupera el motivo trascendental del "J uicio", realizado con la impronta elemental de la madera carcomida y la greda cocida. Como contrapartida de una evolución paralela, nos enfrentamos a las "Piedras" de Gazitúa, de las cuales la presente exposición rinde cuentas.

Estas concreciones pétreas, sin duda en su totalidad, muestran la concentración de la atención en la fundamental presencia de la piedra, puesta ahí, elementarísima, constelada y dispuesta en su envoltura originaria, depositaria de la materia del nunca dilucidado y siempre enigmático misterio original.

Goethe expresaba que la "forma (como tal) ya es un misterio para los más" (cito con libertad).

Y estas piedras mínimas - que en sus disposiciones primeras se articulan y desarticulan en uniones inusitadas, ya lo decíamos- se concentran y dispersan, selevantan y extienden, configuran y desarticulan, progresivamente 
sesometen a un proceso de decantación, simplificación, reducción, poblándose de incisiones sutiles, oquedades elementales, fisuras en la piel rotunda de su continuidad envolvente, que permitirán el acceso a sus"moradas interiores", al camino "cordilleras adentro" en busca de aquellos misterios nunca revelados de nuestro singular macizo andino.

צח 



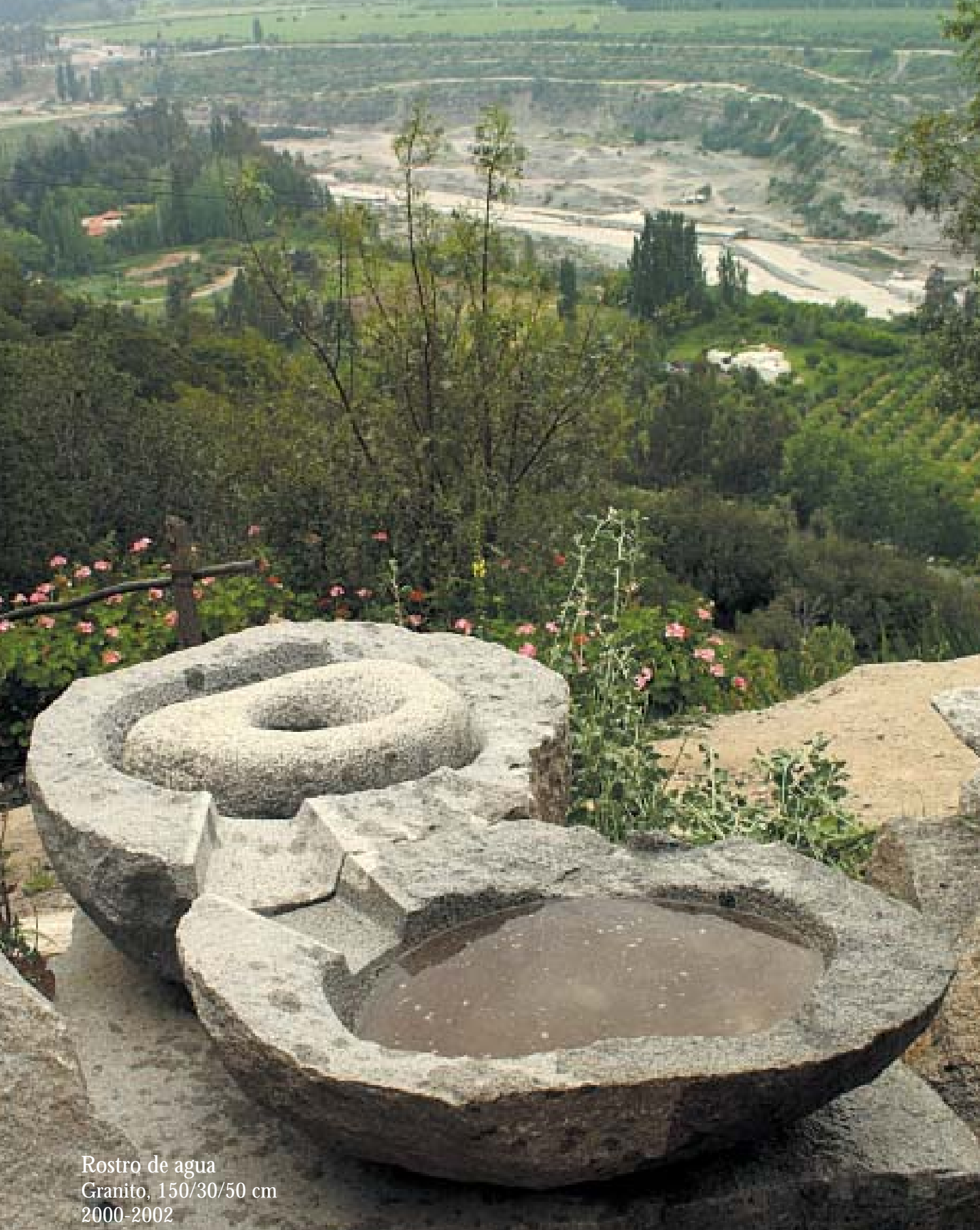

(x) 

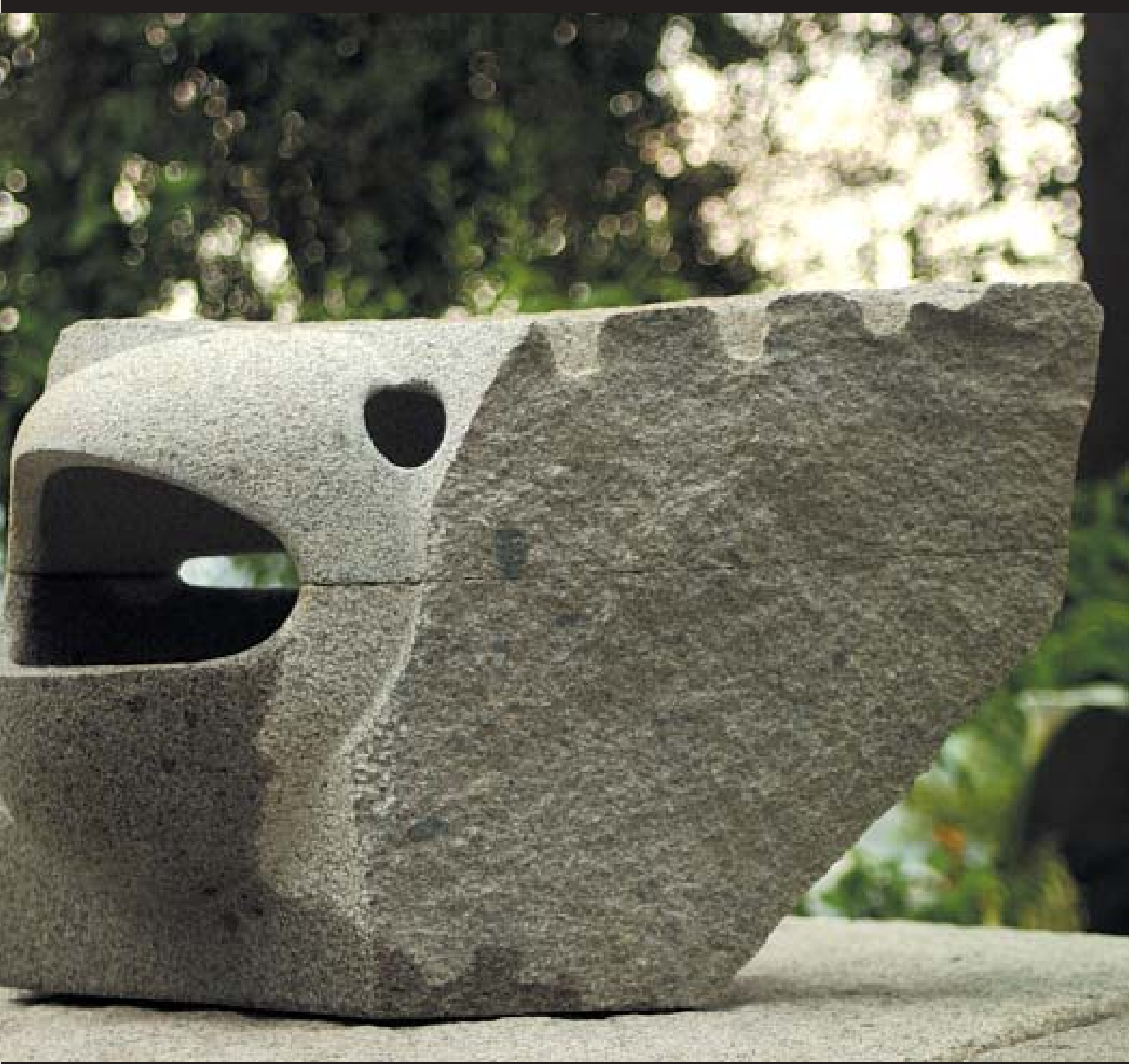

Guerrero Aguila Granito, 60/40/30 cm 


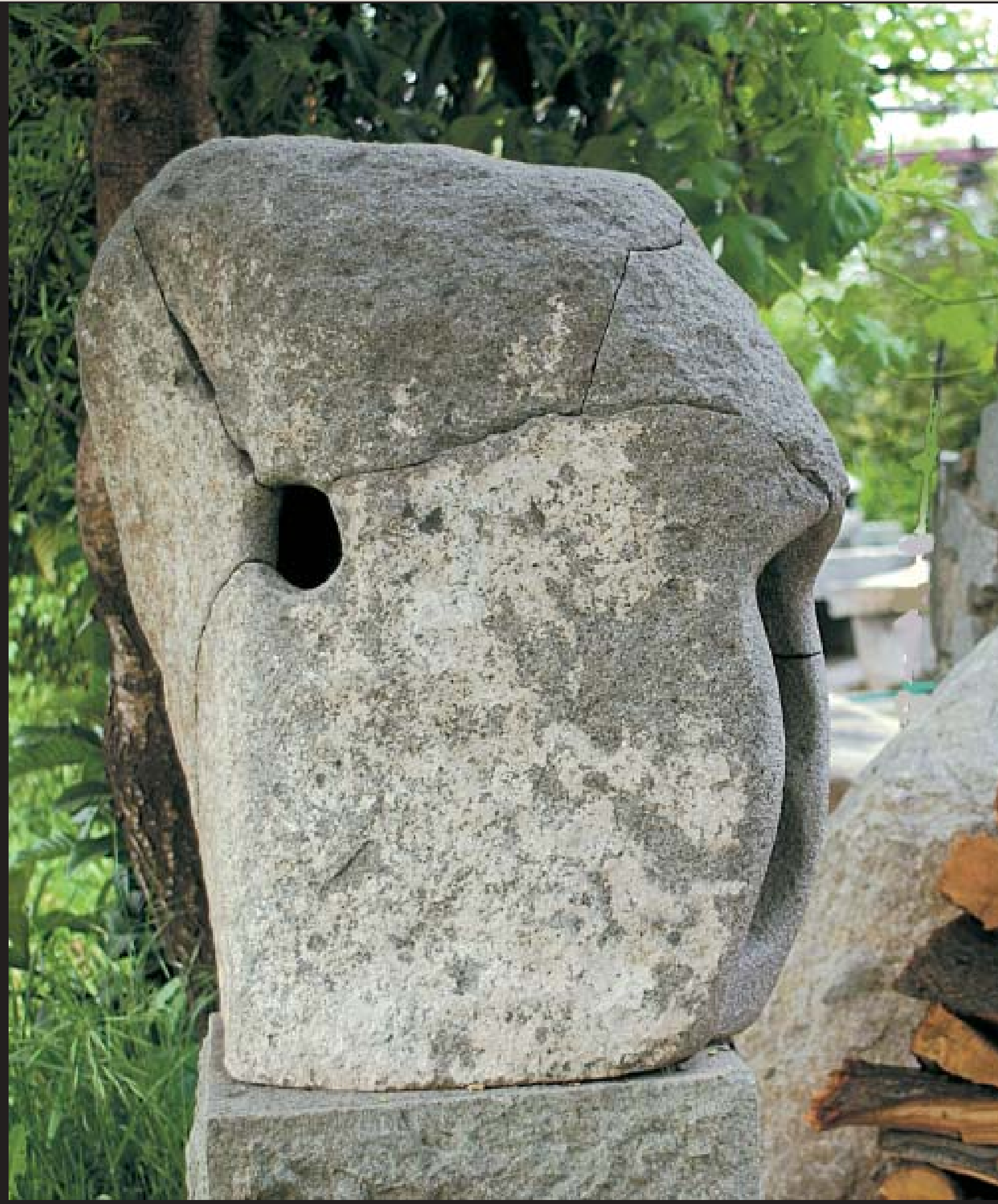




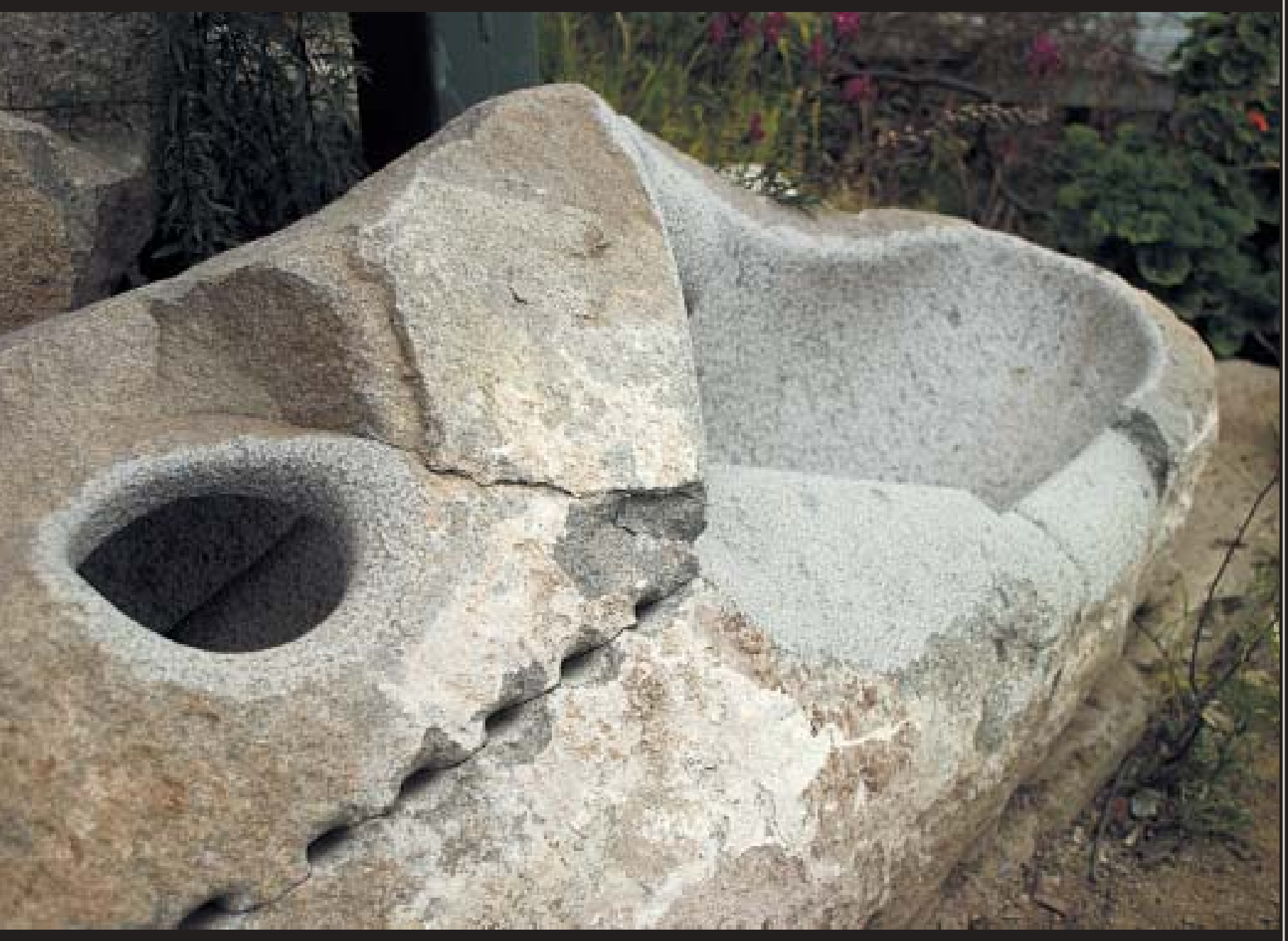

Cráneo de ballena

G ranito, $200 / 100 / 100 \mathrm{~cm}$

2000-2002 


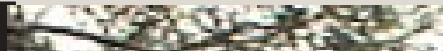

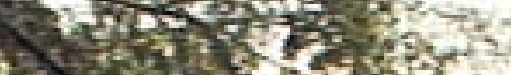

ह.

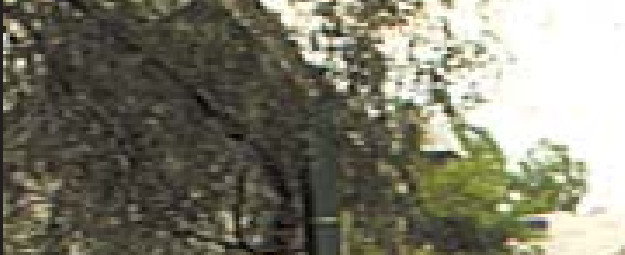

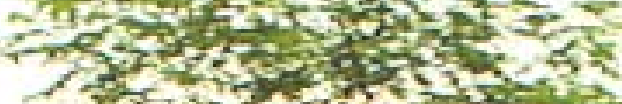

- $\mathrm{N}$ अर्A

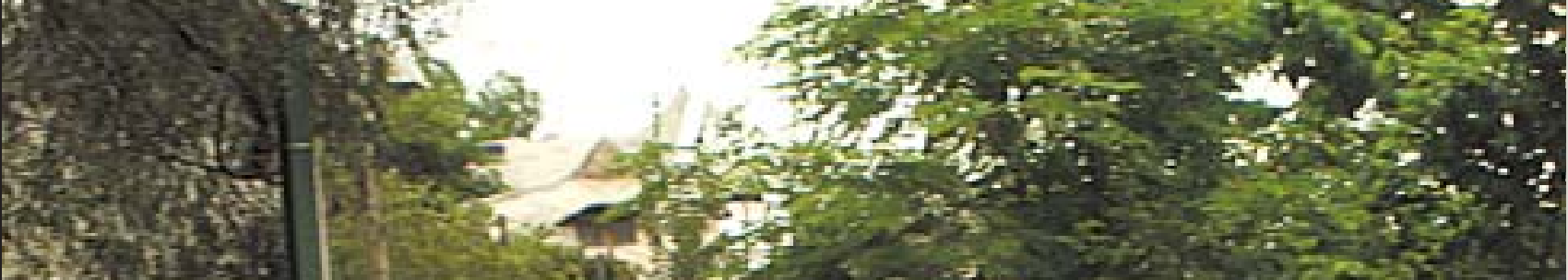

(1)

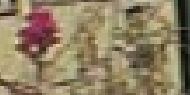

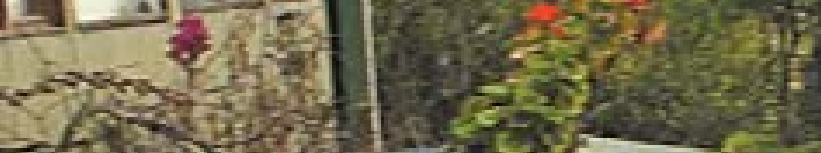

Wif

topts 


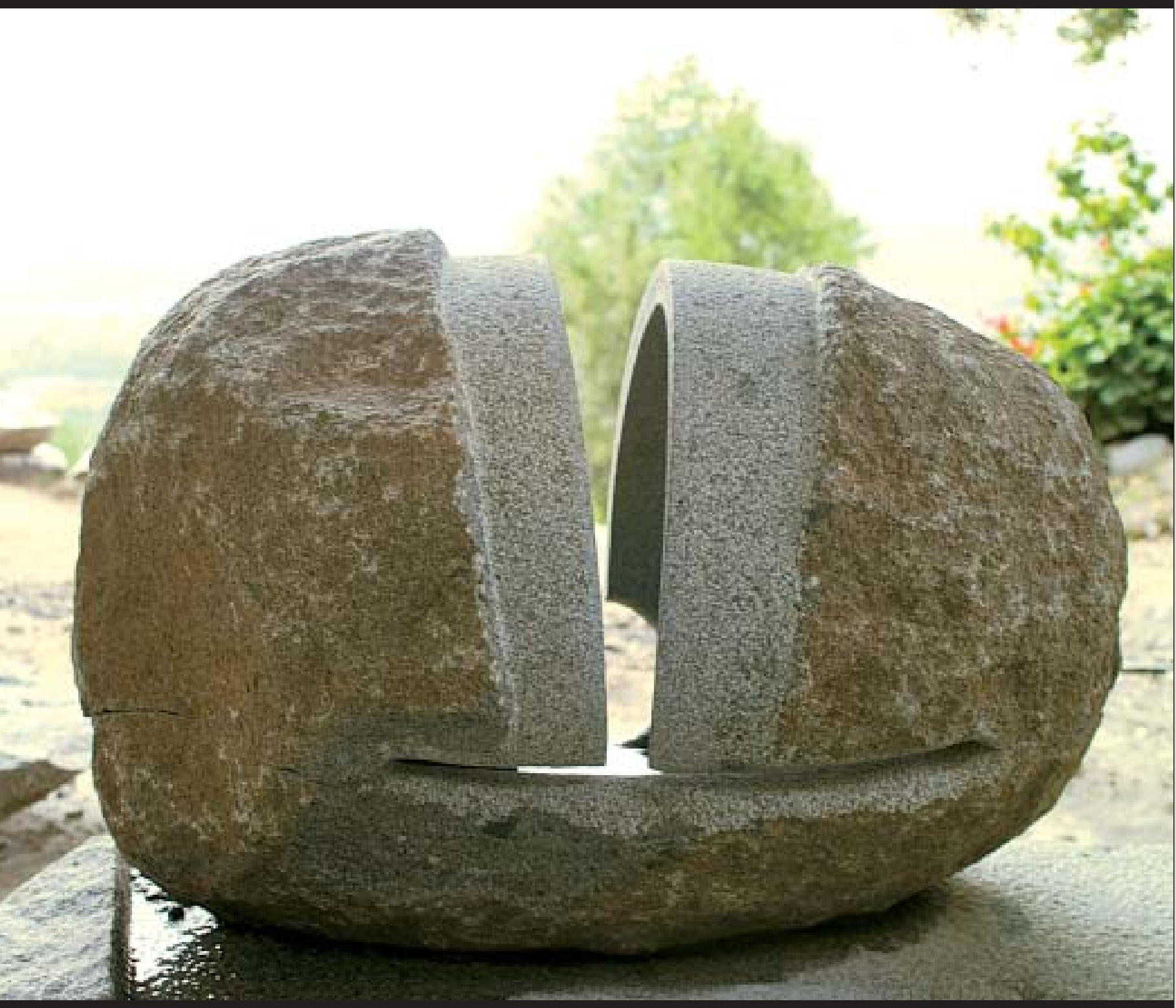

Barcarola

G ranito, $60 / 40 / 50 \mathrm{~cm}$

2000-2002 


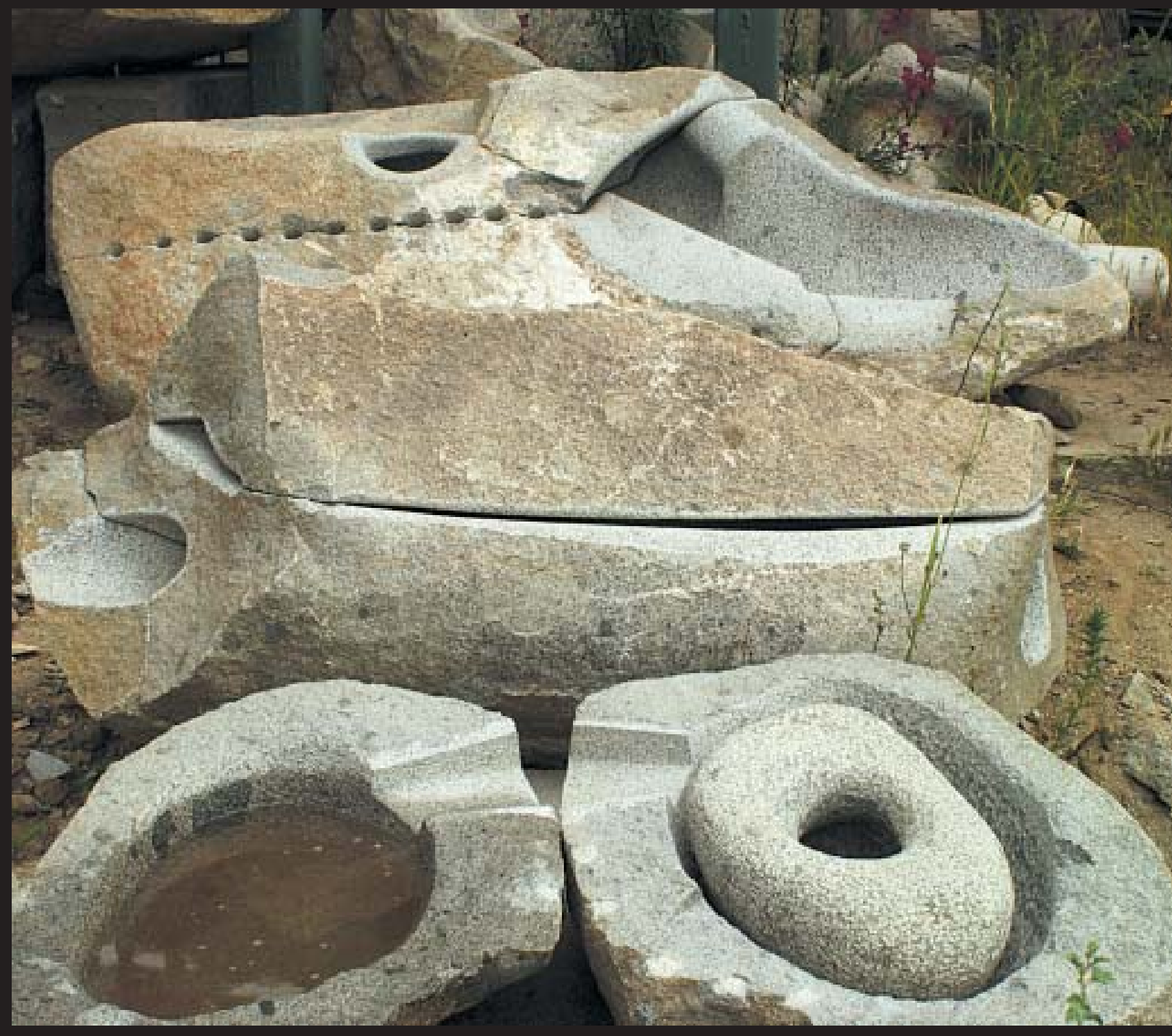

Esculturas en la cantera 
